\title{
METACONTINGÊNCIAS E PRODUTOS AGREGADOS NA LEI DE DIRETRIZES E BASES DA EDUCAÇÃO: PRIMEIRO O OBJETIVO, DEPOIS COMO CHEGAR LÁ
}

\section{METACONTINGENCIES AND AGGREGRATED PRODUCTS IN THE LAW OF GUIDELINES AND BASIS FOR EDUCATION: FIRST THE OBJECTIVE, THEN HOW TO GET THERE}

\author{
IZABEl CRistina VALE de CARVALHO \\ JOÃO CLAUDIO TODOROV \\ UNIVERSIDADE DE BRASÍLIA, BRASIL
}

\section{RESUMO}

Esta pesquisa investigou as relações de contingências e metacontingências contidas na Lei de Diretrizes e Bases da Educação Nacional - LDB. Foram encontradas quatro contingências de reforço, sendo três incompletas e uma completa, que correspondem aos deveres do Estado e da família com a educação, principalmente com o ensino fundamental. Quanto às análises de metacontingências, a LDB define um produto agregado (pleno desenvolvimento do educando) que depende dos outros (preparação para o exercício da cidadania e qualificação o para trabalho), encontrados na educação básica. A Lei é caracterizada principalmente como uma cadeia de produtos agregados.

Palavras-chave: $L D B$, contingências, metacontingências, produto agregado, educação.

This research investigated contingencies and metacontingencies described by the Brazilian Law of Education. Four behavioral contingencies and several metacontingencies, were detected in the text. The law defines an aggregate product (full development of the learner) that depends on other products (preparation for citizenship and qualification for work), found in basic education. The importance of the fundamental school as the basis of education is stressed. The law is characterized as mainly a chain of aggregate products.

Keywords: $L D B$, contingencies, metacontingencies, aggregrated product, education.

\footnotetext{
Trabalho baseado na dissertação de mestrado de Izabel Carvalho no Programa de Pós-Graduação em Ciências do Comportamento do Instituto de Psicologia da Universidade de Brasília. Izabel Carvalho está fazendo doutorado no mesmo programa, com bolsa da CAPES. João Claudio Todorov é Bolsista de Produtividade em Pesquisa 1D do CNPq e Professor Emérito e Pesquisador Voluntário da Universidade de Brasília. Os autores agradecem a Lincoln da Silva Gimenes, Christian Vichi e Laércia Abreu Vasconcelos por suas contribuições. E-mail para contato: joaoclaudio.todorov@gmail.com e izabel.vale@yahoo.com.br
} 
Práticas culturais são padrões de comportamento similares, regidos por contingências sociais de uma determinada cultura, que se reproduzem entre indivíduos e ao longo de gerações de indivíduos (Glenn, 1991, 2004, 2010; Todorov, 2012a, 2012b, 2013). Um conjunto particular de práticas culturais pode ser controlado por grupos bem organizados, por possuírem o poder de manipular variáveis que afetam o comportamento de seus membros. Skinner (1953) discute algumas agências de controle, grupos que manipulam conjuntos específicos de variáveis, como religião, governo, psicoterapia, educação e economia (Dietrich, Todorov, Martone \& SénéchalMachado, 2013). Dentre estas se destaca o governo, cujo controle torna-se mais refinado com a criação de agências legais, como o poder legislativo, e cuja função é codificar as práticas de controle das agências governamentais, o poder executivo, por meio da elaboração de leis.

A lei consiste em uma norma, elaborada pela autoridade de governo e tornada obrigatória para regular a convivência em uma comunidade. $\mathrm{Na}$ perspectiva da Análise do Comportamento, as leis são codificações de procedimentos de controle, enunciados de contingências de reforço e metacontingências, mantidas por uma agência governamental (Todorov, 1991, 2005, 2009). No dizer de B. F. Skinner: "Uma lei é uma regra de conduta, no sentido de que especifica as consequências de certas ações que, por seu turno, regem o comportamento." (Skinner, 1953/2000, p.370).

Leis são descrições de tríplices contingências (Skinner, 1953/2000; Todorov, 1991, 2005, 2012b): cada um de seus artigos pode descrever antecedentes, comportamentos, ou consequências mantidas por uma agência governamental. Além de especificar o comportamento esperado, a lei descreve também consequências para seu cumprimento ou descumprimento, além de especificar as circunstancias nas quais a contingência está em vigor (Skinner, 1953/2000; Todorov, 2005). Leis também podem ter redação menos pormenorizada, especificando apenas metas e objetivos, deixando para outras agências de controle (Dietrich et al., 2013) decisões sobre como alcançar tais objetivos.

A lei pode ser curta, tratar de poucos assuntos, e especificar contingências comportamentais, como a lei da remição de pena para detentos, recentemente aprovada. Outras podem ser mais abrangentes e menos pormenorizadas, especificando produtos agregados, sem especificar as respectivas contingências comportamentais entrelaçadas necessárias para que ocorra o produto agregado. A LDB, Lei de Diretrizes e Bases da Educação Nacional (Lei Federal no. 9394/96), publicada no Diário Oficial da União em 20 de dezembro de 1996, parece se enquadrar no segundo tipo.

\section{Metacontingência}

Most known human cultures include many complex organizations such as schools, unions, companies, non-profits, laboratories, restaurants, etc. The function of these organizations is to provide a product that satisfies requirements of its recipients. The recipients may be external individuals or other organizations, or they may be the members of the organization itself. The product is an aggregate product that is the result of recurring interrelated operants of multiple individuals. (Malott \& Glenn, 2006, pp. 37-38).

Uma metacontingência descreve relações entre contingências comportamentais entrelaçadas (CCEs, que caracterizam colaboração entre pessoas), o efeito comum no ambiente (um produto agregado, PA) e uma consequência programada pelo ambiente cultural selecionador, contingente à ocorrência do produto agregado. Da mesma maneira que as contingências respondentes e operantes descrevem relações entre eventos (entre eventos do ambiente no comportamento respondente, e entre comportamento e ambiente no operante), de acordo com o enunciado "se... então", a metacontingência descreve a relação "se PA, então consequência cultural". Se um determinado produto agregado ocorre, produzido por CCEs, então haverá uma consequência cultural. Um produto agregado é o resultado de contingências tríplices entrelaçadas que envolvem pelo menos duas pessoas. Pode ser um jantar preparado em conjunto por um casal, a música tocada por um conjunto, o dinheiro obtido por um assalto a banco realizado por uma quadrilha (Todorov, 2010).

\section{Metacontingência e Leis}

Todorov, Moreira, Prudência e Pereira (2004) analisaram o Estatuto da Criança e do Adolescente (ECA) em termos de metacontingências e de contingências. Esta lei descreve contingências entrelaçadas de diversos segmentos da sociedade, cuja consequência cultural, em longo prazo, é a proteção integral de crianças e adolescentes. Os autores identificaram as contingências tríplices entrelaçadas representadas nos artigos do ECA, agrupando-os em antecedentes, comportamentos e consequências de uma mesma contingência.

$\mathrm{O}$ procedimento consistiu, primeiramente, na localização de um artigo do ECA que descrevesse um comportamento (ação esperada). Em seguida, procurou-se outros artigos que se apresentassem como antecedentes ou consequências contingentes a esse comportamento. Com a formação das contingências, estas foram classificadas em completas: aquelas que possuíam os três termos da contingência ou que possuíam apenas comportamento e consequência; ou em incompletas: aquelas que possuíam apenas um ou dois termos da contingência. Como resultado da análise, observou-se no ECA o percentual de $47,2 \%$ de contingências completas e de $52,8 \%$ de contingências incompletas. Os autores também identificaram 29 grupos de metacontingências secundárias, além da metacontingência primária, entre elas: Saúde, Família, Liberdade, Educação, Guarda, Tutela, Pátrio Poder, e outros.

Outras pesquisas utilizaram esse procedimento para analisar outras leis, como as Leis Orgânicas da Saúde (Martins, 2008), o Regimento Interno e Estatuto de uma cooperativa de produção de lixo reciclável (Silva, 2008).

O presente trabalho usou esse procedimento desenvolvido por Todorov et al. (2004) para analisar a 
$L D B$ enquanto possível descrição de contingências e metacontingências.

Entre os objetivos específicos estão:

- Identificar tríplices contingências, a partir dos artigos contidos na lei;

- Classificar as contingências em completas e incompletas;

- Completar as contingências incompletas com outros artigos da $L D B$ ou com artigos de leis correlatas;

- Identificar os PAs a partir da metacontingência principal, que rege toda a $L D B$;

- Definir os PAs de cada metacontingência em PAs primários, e estes definirem em secundários, estes em terciários, e assim por diante.

\section{MÉTODO}

\section{Objeto do Estudo}

A presente pesquisa teve como objeto de estudo os artigos presentes na Lei de Diretrizes e Bases da Educação Nacional (Lei 9394/96). Esta lei é constituída por 92 artigos, organizados em nove Títulos, cinco Capítulos, e cinco Seções. Ela define e regulariza o sistema de educação do Brasil, com base nos princípios presentes na Constituição Brasileira, e no princípio do direito universal à educação para todos.

Conforme a $L D B$, a educação brasileira é composta por dois níveis, a educação básica e o ensino superior. A educação básica é constituída por: educação infantil, gratuita e não obrigatória; ensino fundamental, gratuito e obrigatório; e ensino médio, de universalização progressiva, podendo ser técnico profissionalizante ou não. A $L D B$ ainda apresenta as seguintes modalidades: Educação Especial, Educação a distância, Educação Profissional e Tecnológica, Educação de Jovens e Adultos, e Educação Indígena.

\section{Procedimento}

A metodologia deste estudo é descritiva, voltada à sistematização das contingências e metacontingências presentes na Lei e Diretrizes de Base da Educação Nacional - LDB. O procedimento conta com duas etapas, sendo a primeira uma replicação sistemática do procedimento de Todorov et al. (2004).

$\mathrm{Na}$ identificação dos termos das contingências, cada artigo poderia se referir a um antecedente, um comportamento ou uma consequência, conforme os seguintes critérios:

- Antecedente: o artigo descreve contextos, condições e circunstâncias para a ocorrência do comportamento.

- Comportamento: o artigo estabelece a ação esperada de um sujeito, a qual pode ser definida implícita ou explicitamente.

- Consequência: são consequências diretas de comportamentos definidos nas contingências.

Com a formação das contingências, estas foram classificadas em completas ou incompletas. Diferente das outras pesquisas que utilizaram este procedimento, nesta pesquisa quando uma contingência foi classificada como incompleta, procurou-se em outros códigos de lei que também abordam o tema de direito à educação (Constituição Federal e no Estatuto da Criança $e$ Adolescente), artigos que possam completar tais contingências incompletas.

A segunda etapa refere-se à identificação e sistematização de produtos agregados (PAs) contidos nas metacontingências presentes na $L D B$. A partir da metacontingência principal, que rege toda a lei, buscou-se identificar os PAs, que chamaremos de PAs Principais. Em seguida, estes PAs primários foram definidos em PAs secundários e terciários, por meio da seguinte pergunta: "Que outros PAs são necessários serem produzidos para alcançar este PA?”.

\section{RESULTADOS}

A primeira parte dos resultados refere-se à identificação e descrição de tríplices contingências, de acordo com os artigos dispostos na $L D B$, e sua classificação em completas e incompletas. Na segunda parte foram feitas a identificação de produtos agregados (PA) e sua categorização em primários, secundários, e assim por diante, a partir dos artigos da lei.

\section{Tríplices Contingências}

Segundo o Art. $2^{\circ}$ da $L D B$, a educação é dever do Estado e da família. A partir deste artigo foram procurados quais comportamentos descreveriam exatamente esses deveres, em que circunstâncias eles deveriam ocorrer, e as consequências contingentes a esses comportamentos.

Dever implica comportamento quando se trata de garantia dos direitos sociais, pois estes são obrigações que ditam o que o Estado tem que fazer para o povo (Moraes, 2001). Partindo disso, os deveres com a educação são comportamentos a serem emitidos pelo Estado e pela família.

Foram encontradas quatro contingências de reforço, sendo três incompletas, e a outra, além de ser completa, é também dividida em três contingências completas, conforme a Tabela 1.

De acordo com o Art. $4^{\circ}$ da $L D B$, o dever do Estado corresponde à garantia de oferta e acesso gratuito a todos os níveis de ensino, inclusive educação especial e educação para jovens e adultos, além de padrões mínimos de qualidade. Porém, conforme Inciso I do Art. $4^{\circ}$ e $\S 2^{\circ}$ do Art. $5^{\circ}$, apenas o ensino fundamental é tido como obrigatório e prioridade inicial do poder público.

Os deveres do Estado, descritos no Art. $4^{\circ}$, têm como antecedentes o Art. $2^{\circ}$ da $L D B$ e o Art. 205 da Constituição (para tornar mais claro o artigo da $L D B$ ). Para o comportamento "garantir o ensino obrigatório" (ensino fundamental) foi identificado, no $\S 4^{\circ}$ do Art. $5^{\circ}$ da $L D B$, consequência contingente ao seu não cumprimento pelas autoridades competentes, que corresponde a crime por responsabilidade (ver Tabela 2). 
Tabela 1.

Tríplices Contingências Completas e Incompletas Identificadas a Partir dos Deveres do Estado e da Família.

\begin{tabular}{|c|c|c|}
\hline \multirow[t]{3}{*}{$\begin{array}{l}\text { Tríplices Contingências } \\
\text { Completas }\end{array}$} & \multirow[t]{3}{*}{$\begin{array}{l}\text { Dever do Estado - Garantir o } \\
\text { ensino fundamental }\end{array}$} & $\begin{array}{l}\text { Estado }- \text { Oferta do ensino } \\
\text { fundamental }\end{array}$ \\
\hline & & $\begin{array}{l}\text { Município - Oferta do ensino } \\
\text { fundamental }\end{array}$ \\
\hline & & $\begin{array}{l}\text { União }- \text { Assistência técnica e } \\
\text { financeira }\end{array}$ \\
\hline \multirow{3}{*}{$\begin{array}{l}\text { Tríplices Contingências } \\
\text { Incompletas }\end{array}$} & \multicolumn{2}{|l|}{ Demais deveres do Estado } \\
\hline & \multicolumn{2}{|c|}{$\begin{array}{l}\text { Dever da família - Efetuar a matrícula dos menores no ensino } \\
\text { fundamental }\end{array}$} \\
\hline & \multicolumn{2}{|c|}{$\begin{array}{l}\text { Ação da família - Acompanhar a frequência escolar no ensino } \\
\text { fundamental }\end{array}$} \\
\hline
\end{tabular}

Tabela 2.

Tríplice Contingência Completa Referente ao Comportamento "Garantir o Ensino Fundamental", Dever do Estado.

\begin{tabular}{|c|c|c|}
\hline ANTECEDENTE & $\begin{array}{c}\text { COMPORTAMENTO } \\
\text { Garantia do ensino obrigatório } \\
\text { (ensino fundamental) }\end{array}$ & CONSEQUÊNCIA \\
\hline $\begin{array}{l}\text { Art. } 2^{\circ} \text { A educação, dever da } \\
\text { família e do Estado, inspirada nos } \\
\text { princípios de liberdade e nos ideais } \\
\text { de solidariedade humana, tem por } \\
\text { finalidade o pleno } \\
\text { desenvolvimento do educando, seu } \\
\text { preparo para o exercício da } \\
\text { cidadania e sua qualificação para o } \\
\text { trabalho. }\end{array}$ & $\begin{array}{l}\text { Art. } 4^{\circ} \mathrm{O} \text { dever do Estado com a } \\
\text { educação escolar pública será } \\
\text { efetivado mediante a garantia de: } \\
\mathrm{I} \text { - ensino fundamental, obrigatório } \\
\text { e gratuito }{ }^{\text {a }} \text {, inclusive para os que a } \\
\text { ele não tiveram acesso na idade } \\
\text { própria. }\end{array}$ & \begin{tabular}{lrrr} 
Art. $\left.5^{\circ}\right)$ & $4^{\circ}$. Comprovada & Co \\
negligência & da & \multicolumn{2}{c}{ autoridade } \\
competente & para & garantir & o \\
oferecimento & \multicolumn{2}{c}{ do } & ensino \\
obrigatório, poderá ela & ser \\
imputada por & crime & de \\
responsabilidade. & &
\end{tabular} \\
\hline $\begin{array}{l}\text { Art. } 5^{\circ} \text { O acesso ao ensino } \\
\text { fundamental é direito público } \\
\text { subjetivo, (...) }\end{array}$ & $\begin{array}{l}\left(\text { Art. } 5^{\circ}\right) \S 2^{\circ} \text { Em todas as esferas } \\
\text { administrativas, o poder público } \\
\text { assegurará em primeiro lugar o } \\
\underline{\text { acesso ao ensino obrigatório, }(\ldots)}\end{array}$ & \\
\hline
\end{tabular}

Os demais deveres do Estado para com a educação dizem respeito ao atendimento gratuito da educação infantil, ensino médio, educação de jovens e adultos, acesso aos níveis mais elevados de ensino e pesquisa, e padrões mínimos de qualidade. Para estes não foram encontradas, nem na $L D B$ e nem na Constituição ou no ECA, consequências contingentes ao seu cumprimento pelos agentes competentes. Por conter apenas antecedente e comportamento, tal contingência é incompleta, conforme mostrado na Tabela 3.

Enquanto para o dever (comportamento) "garantir o ensino obrigatório/fundamental", o antecedente continua sendo o Art. 205 da Constituição e Art. 2 da $L D B$, acrescido o Art. 5 desta que especifica a prioridade deste ensino, a não ocorrência deste comportamento tem como consequência as penalidades por crime de responsabilidade, descritas no Parágrafo $4^{\circ}$ do Art. 5 da $L D B$. Esta é a tríplice contingência completa, por conter antecedente, comportamento e consequência.

A única consequência contingente aos deveres do Estado encontrada na $L D B$ diz respeito à garantia de oferta do ensino fundamental. Os agentes diretamente responsáveis pela oferta são os estados, os municípios e Distrito Federal, conforme Capítulo VI do Art. 10, Capítulo V do Art. 11, e Parágrafo único de Art. 10 da $L D B$, respectivamente. Enquanto isso, a União é responsável por prestar assistência técnica e financeira a estes agentes para o desenvolvimento dos sistemas de ensino, dando prioridade ao ensino fundamental, de acordo com Capítulo III do Art. 9. 
Tabela 3.

Tríplice Contingência Incompleta Referente ao Comportamento "Garantia dos Demais Níveis de Ensino e Padrões Mínimos de Qualidade”, Dever do Estado.

\begin{tabular}{|c|c|c|}
\hline ANTECEDENTE & COMPORTAMENTO & CONSEQUÊNCIA \\
\hline $\begin{array}{l}\frac{L D B}{A r t} 2^{\circ} \text { A educação, dever da família } \\
\text { e do Estado, inspirada nos princípios } \\
\text { de liberdade e nos ideais de } \\
\text { solidariedade humana, tem por } \\
\text { finalidade o pleno desenvolvimento } \\
\text { do educando, seu preparo para o } \\
\text { exercício da cidadania e sua } \\
\text { qualificação para o trabalho. } \\
\text { Constituição } \\
\text { Art. 205. A educação, direito de } \\
\text { todos e dever do Estado e da família, } \\
\text { será promovida e incentivada com a } \\
\text { colaboração da sociedade, visando ao } \\
\text { pleno desenvolvimento da pessoa, } \\
\text { seu preparo para o exercício da } \\
\text { cidadania e sua qualificação para o } \\
\text { trabalho. }\end{array}$ & $\begin{array}{l}\text { Garantia de demais níveis de ensino e } \\
\text { padrões mínimos de qualidade. } \\
\text { Art. } 4^{\circ} \text { O dever do Estado com a } \\
\text { educação escolar pública será efetivado } \\
\text { mediante a garantia de: } \\
\text { Capítulos II a X }\end{array}$ & $\begin{array}{c}\text { Não encontrado na } \\
\text { Constituição nem no ECA }\end{array}$ \\
\hline
\end{tabular}

A partir desta contingência foram encontradas outras três contingências contendo o mesmo antecedente, e os comportamentos correspondentes a "oferta do ensino fundamental" cujos responsáveis são os agentes que representam os municípios (prefeitos e vereadores), os estados (governadores e secretários de estado) e o Distrito Federal (governador e secretários), e cujas consequências por crime de responsabilidade são descritas, respectivamente, no Inciso $\S 2^{\circ}$ do Art. $1^{\circ}$ do Decreto de Lei $N^{\circ} 201 / 67$, Art. 78 da Lei $N^{o} 1.079 / 50$ e Art. $4^{\circ}$ da Lei $N^{o} 7.106 / 83$, que se resumem à perda de cargo e inabilitação para exercício de qualquer função pública por até cinco anos, caso seja comprovada tal negligência. A União tem como comportamento a "assistência técnica e financeira" para o desenvolvimento dos sistemas de ensino, priorizando o ensino fundamental, e tem as mesmas consequências por crime de responsabilidades, descrito no Art. $2^{\circ}$ da Lei $N^{\circ} 1.079 / 50$.

Assim, temos uma tríplice contingência completa e, a partir desta, foram descritas outras quatro tríplices contingências, cujo comportamento de cada agente é a oferta do ensino fundamental, tendo o mesmo antecedente da principal, porém suas consequências, apesar de serem descrições da consequência da primeira tríplice contingência, foram encontradas em outras leis, por serem mais específicas e contingentes ao comportamento de cada agente.

O dever da família, por sua vez, foi encontrado no Art. $6^{\circ}$, no qual o comportamento exigido é apenas a efetuação da matrícula dos menores no ensino obrigatório (fundamental), a partir dos seis anos de idade. $\mathrm{O}$ antecedente deste comportamento é o Art. $2^{\circ}$ e Art. $5^{\circ}$ da $L D B$; entretanto, não foi encontrada na referida lei qualquer consequência contingente a este comportamento. Por isso recorreu-se a outras leis para completar essa contingência; assim a consequência para o descumprimento deste artigo foi encontrada no Art. 24 e Art. 249 do Estatuto da Criança e Adolescente (ECA).

Observa-se que o dever da família se restringe apenas à efetuação da matrícula de seus filhos no ensino fundamental. Entretanto foi encontrada na $L D B$ outra atividade da família, que diz respeito ao acompanhamento da frequência escolar dos mesmos, mas esta ação não é vista como dever explícito, conforme o capítulo II do Inciso $\S 1^{\circ}$ do Art. $5^{\circ}$, e Capítulo VII do Art. 12. Entretanto, no ECA "acompanhar frequência escolar" é tido como obrigação da família (V do Art. 129) e tem como consequência pelo seu descumprimento, de dever inerente ao pátrio poder, a pena correspondente ao Art 249.

A partir dessas análises, observa-se que a família tem duas ações referentes à educação, matricular os filhos no ensino fundamental, este sendo um dever, e acompanhar a frequência escolar dos mesmos, não visto como dever explícito. A consequência de ambos foi encontrada em outras leis: o ECA e a Lei $n^{\circ} 10.836 / 04$, respectivamente. Por recorrer a outras leis para identificar consequências contingentes às ações da família, as contingências são incompletas, tendo apenas o antecedente e comportamento identificados na $L D B$, conforme ilustrado na Figura 2. 


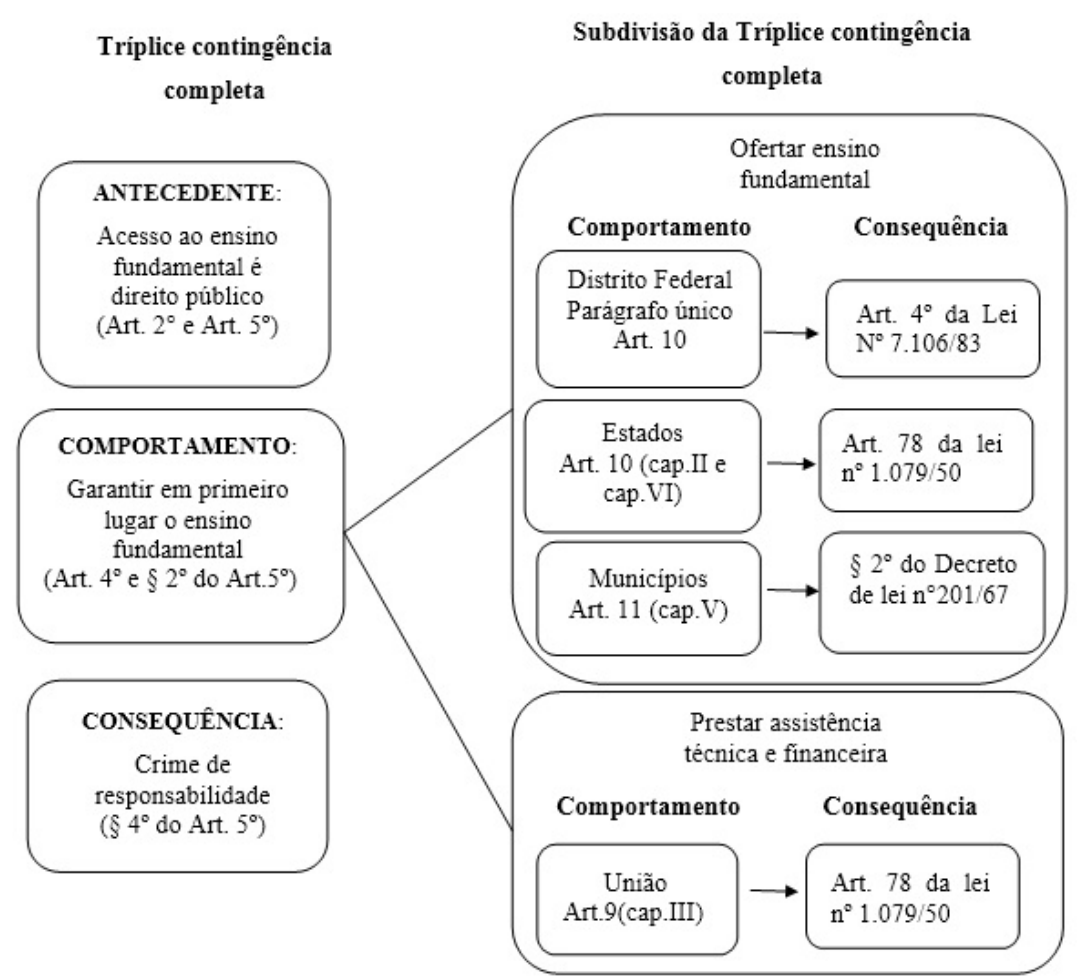

Figura 1. Tríplice contingência completa e sua subdivisões referentes a ações do Estado, com especificações de comportamentos e suas consequências.

Tabela 4.

Tríplice Contingência Incompleta do Dever da Família, Completada com Consequências Encontradas no ECA.

\begin{tabular}{|c|c|c|}
\hline ANTECEDENTE & $\begin{array}{c}\text { COMPORTAMENTO } \\
\text { "Efetuar matrícula" }\end{array}$ & CONSEQUÊNCIA \\
\hline $\begin{array}{l}\text { Art. } 2^{\circ} \text { A educação, dever da } \\
\text { família e do Estado, inspirada } \\
\text { nos princípios de liberdade e } \\
\text { nos ideais de solidariedade } \\
\text { humana, tem por finalidade o } \\
\text { pleno desenvolvimento do } \\
\text { educando, seu preparo para o } \\
\text { exercício da cidadania e sua } \\
\text { qualificação para o trabalho. }\end{array}$ & 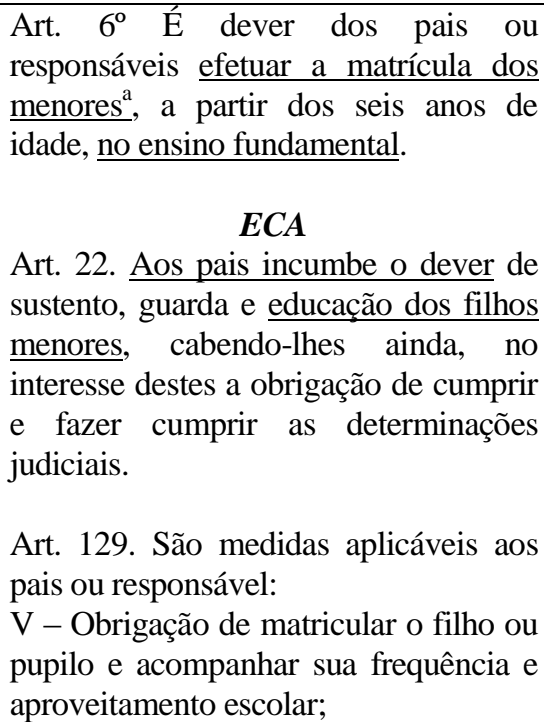 & $\begin{array}{l}\text { ECA } \\
\text { Art. 24. A perda e a suspensão do poder } \\
\text { familiar serão decretadas judicialmente, } \\
\text { em procedimento contraditório, nos } \\
\text { casos previstos na legislação civil, bem } \\
\text { como na hipótese de descumprimento } \\
\text { injustificado dos deveres e obrigações a } \\
\text { que alude o Art. } 22 \text {. } \\
\text { Art. } 249 \text {. Descumprir, dolosa ou } \\
\text { culposamente, os deveres inerentes ao } \\
\text { poder familiar ou decorrente de tutela ou } \\
\text { guarda, bem assim determinação da } \\
\text { autoridade judiciária ou Conselho } \\
\text { Tutelar: } \\
\text { Pena - multa de três a vinte salários de } \\
\text { referência, aplicando-se o dobro em caso } \\
\text { de reincidência. }\end{array}$ \\
\hline
\end{tabular}

${ }^{\text {a }}$ Grifo acrescentado

\section{Metacontingências}

No Art. 2 é descrita a metacontingência principal que rege toda a $L D B$, e que abarca metacontingências secundárias, conforme os PAs especificados.

Art. $2^{\circ}$ A educação, dever da família e do Estado, inspirada nos princípios de liberdade e nos ideais de solidariedade humana, tem por finalidade o pleno desenvolvimento do educando, seu preparo para o exercício da cidadania e sua qualificação para o trabalho. 


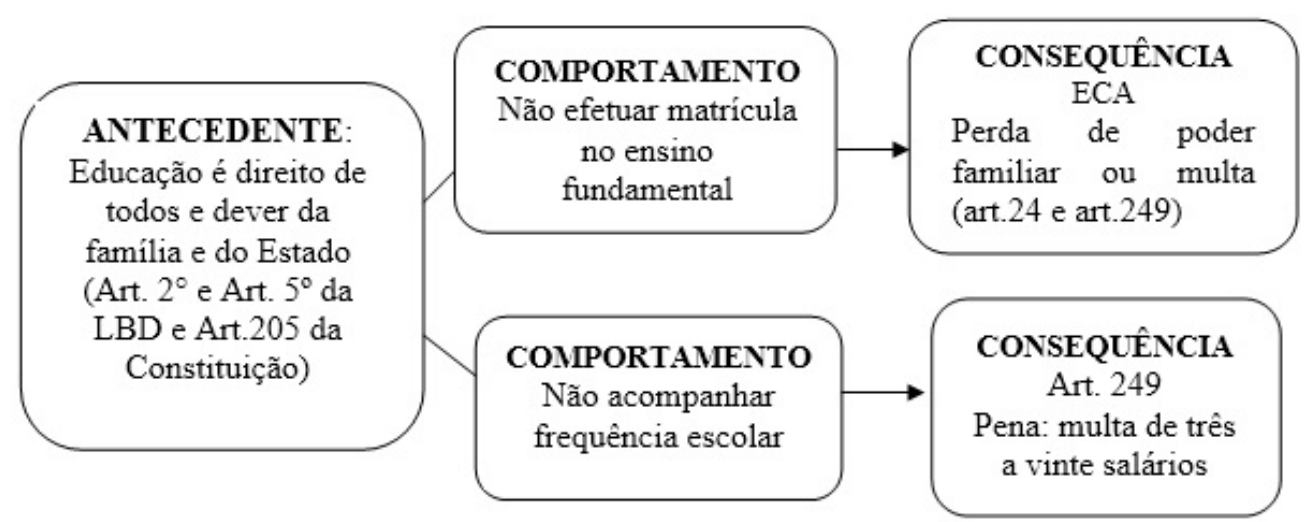

Figura 2. Tríplices contingências incompletas referentes a ações da família, sendo completadas com outras leis.

Como objetivos da educação, encontramos aqui os seguintes PAs: pleno desenvolvimento, preparo para o exercício da cidadania, e qualificação para o trabalho. A partir deste, para a definição de outros possíveis PAs, foi utilizada a seguinte pergunta norteadora: "Que outros PAs são necessários serem produzidos para alcançar este $P A$ ? " Como resultado, para cada PA da metacontingência principal foram definidos outros PAs, conforme será discutido a seguir.

No PA "pleno desenvolvimento", ao tentar responder a pergunta norteadora, "Que outros PAs são necessários serem produzidos para alcançar esse PA?", podemos compreender sua definição como produto de outros PAs definidos na metacontingência principal, preparo para o exercício da cidadania e qualificação para o trabalho, em termos da função da educação. Ou seja, para que haja um pleno desenvolvimento do educando, é necessário que este esteja preparado para exercer sua cidadania e que esteja qualificado para executar alguma atividade profissional.

Assim, na metacontingência descrita no Art.2 observamos o PA primário "pleno desenvolvimento do educando" sendo definido pelos PAs secundários "preparo para o exercício da cidadania" e "qualificação para o trabalho". Cada PA secundário corresponde a uma metacontingência secundária, por ele definido. Ou seja, a metacontingência principal contém duas metacontingências secundárias, oriundas da definição de cada PA.

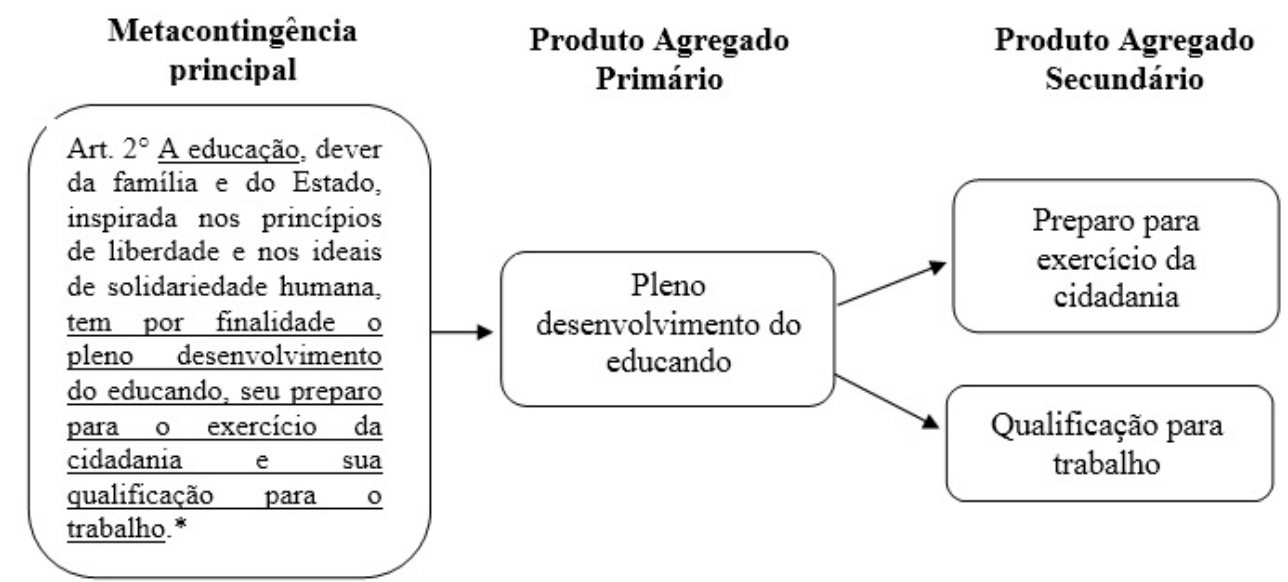

Figura 3. Definição de produtos agregados primários e secundários a partir da metacontingência principal. * Grifo acrescentado.

De acordo com a $L D B$, a educação básica, formada por ensino infantil, fundamental e médio, é responsável pelos dois PAs secundários, preparo para o exercício da cidadania e qualificação para o trabalho. Logo, pressupõe-se que as definições destes serão encontradas nestes níveis de ensino.

Segundo o dicionário Aurélio, "cidadania" significa "condição de cidadão", e "cidadão" é "indivíduo no gozo dos direitos civis e políticos de um Estado." Assim, podemos compreender que exercer cidadania significa exercer os direitos e deveres civis e políticos, sendo estes descritos na Constituição Brasileira. Para o exercício destes é necessário conhecê-los, mas como tais conhecimentos podem ser adquiridos? Nem na educação formal nem informal eles são diretamente ensinados, mesmo sendo eles especificados como uma das diretrizes para os conteúdos curriculares da educação básica.

Por outro lado, o conhecimento da história social, política e cultural da sociedade, além dos valores da sociedade, também constituem preparo para exercício da 
cidadania. Diante disso, ao responder a pergunta "Que outros PAs são necessários serem produzidos para alcançar este PA?" para a definição do PA secundário "exercício da cidadania" foram encontrados os repertórios do educando no conhecimento da história política e social, e da cultura do Brasil. Eles são descritos nos currículos comuns do ensino fundamental e médio (Art. 26 e Art. 26A da $L D B)$.

Desta forma, o PA secundário "preparo para exercício da cidadania" é definido por dois grupos de PA terciários, porém apenas o segundo grupo consiste em repertórios que o educando deve apresentar ao final do ensino médio, iniciado no ensino fundamental, como é sintetizado na Tabela 5.
E por último, temos o PA secundário "qualificação para o trabalho". Para este, ao tentar responder a pergunta "Que outros PA são necessários serem produzidos para alcançar este PA secundário?", não foram encontradas habilidades do educando referentes ao trabalho, assim como fora encontrado para o PA "exercício da cidadania", e nem outro tipo de produto agregado.

Entretanto, ao se questionar como chegar a esse PA secundário (qualificação para o trabalho) foram identificados dois níveis de ensino (ensino médio e superior) e três modalidades (Educação Profissional e Tecnológica, Educação de jovens e adultos, Educação Especial) de ensino, estes se integrando aos diferentes níveis de ensino regular.

Tabela 5

Definição do PA Secundário "Preparo para Exercício da Cidadania" em PA's Terciários.

\begin{tabular}{c|cc}
\hline PA Secundário & \multicolumn{1}{c}{ PA Terciário } \\
\cline { 2 - 2 } "Preparo para exercício da cidadania" & a. Conhecimento dos direitos civis e políticos \\
\cline { 2 - 2 } & b. $\begin{array}{l}\text { Conhecimento da história social e política, da cultura } \\
\text { do Brasil, e valores da sociedade. }\end{array}$ \\
\hline
\end{tabular}

O ensino médio tem como objetivo, dentre outros, a preparação básica para o trabalho e compreensão dos fundamentos científico-tecnológicos dos processos produtivos (Parágrafo II e IV do Art. 35). O ensino superior, por sua vez, objetiva formar "diplomados nas diferentes áreas de conhecimento, aptos para a inserção em setores profissionais" (Parágrafo II do Art.43).
A Educação Profissional e Tecnológica, por sua vez, abrange três cursos, cada um ocorrendo paralelo, ou ao final, de um nível de ensino regular, conforme a Tabela 6, e garantindo, ao final, uma certificação de qualificação para trabalho (Art. 39, 40 e 41).

Tabela 6.

Cursos da Educação Profissional e Tecnológica que Ocorrem com Respectivos Níveis do Ensino Regular.

\section{Cursos da Educação Profissional e Tecnológica} Níveis do Ensino Regular

\begin{tabular}{l|l}
\hline $\begin{array}{l}\text { De formação inicial e continuada ou qualificação } \\
\text { profissional; }\end{array}$ & Ensino fundamental \\
\hline De educação profissional técnica de nível médio; & Ensino médio \\
\hline $\begin{array}{l}\text { De educação profissional técnica de graduação e pós- } \\
\text { graduação }\end{array}$ & Ensino superior \\
\hline
\end{tabular}

A Educação Especial é direcionada para educandos portadores de necessidades especiais, sendo oferecida, preferencialmente, no ensino regular, e deve assegurar uma educação voltada para trabalho, visando à inclusão social destes educandos (Art. 58 e 59). A Educação de Jovens e Adultos, que é destinada aos indivíduos que não tiveram acesso ou não concluíram o ensino fundamental e médio na idade própria, deve se articular com a educação profissional (Art.37).

Dentre estas formas de atingir o PA secundário qualificação para o trabalho, apenas no ensino superior e na Educação Profissional e Tecnológica o educando obtém um diploma ou certificado, respectivamente, que comprove a sua qualificação para o mercado de trabalho.

\section{DISCUSSÃO}

A presente pesquisa buscou investigar as contingências e metacontingências contidas na Lei de Diretrizes e Bases da Educação Nacional - LDB. Em termos gerais, observou-se que o Art.2 foi central, tanto para a análise funcional (a partir dos deveres do Estado e da família), como para a análise de metacontingência (com as finalidades da educação).

A partir dos artigos da referida lei, foi encontrada uma tríplice contingência completa e três tríplices contingências incompletas; apenas duas destas foram completadas, em suas consequências, com artigos da Constituição Federal e do Estatuto da Criança $e$ Adolescente (Tabela 1). 
Com os resultados das análises, observa-se que apenas para os comportamentos "garantir oferta e permanência no ensino fundamental" (que incluem acesso, matrícula e frequência) há previsão de consequências contingentes ao descumprimento, tanto por parte do Estado quanto da família.

A tríplice contingência completa encontrada diz respeito ao dever do Estado em garantir o ensino obrigatório (ensino fundamental), cuja consequência pelo descumprimento é a penalidade por crime de responsabilidade. Como Estado é composto pela União, estados-membros, Distrito Federal, municípios, o comportamento "garantir o ensino fundamental" foi dividido conforme estes entes federados: comportamento de "oferecer do ensino fundamental" pelos estados, Distrito Federal e municípios (sendo prioridade deste), e comportamento de "prestar assistência técnica e financeira" para atendimento prioritário do ensino pela União (Figura 1).

As consequências contingentes a esses comportamentos correspondem ao melhor detalhamento do crime de responsabilidade, que se resumem à perda de cargo e inabilitação para o exercício de qualquer função pública, por até cinco anos. Tais consequências são contingentes ao não cumprimento da garantia ao ensino fundamental pelos agentes responsáveis em cada ente federado. Quanto à ausência de oferta ou oferta irregular, Konzen (1999) apresenta também outra penalidade, a improbidade administrativa, na hipótese de desvio de recursos públicos, que seria destinado à educação, para outras finalidades.

A lei de improbidade administrativa (Lei n8.429/92) descreve sanções aplicáveis aos agentes públicos nos casos de enriquecimento ilícito ou danos ao tesouro público durante a administração pública. As penalizações são: perda de bens obtidos ilicitamente, perda da função pública, ressarcimento dos danos materiais, suspensão dos direitos políticos por um determinado período, e multa.

Não foram encontrados na Constituição e no ECA artigos que indiquem consequências contingentes aos demais deveres do estado (garantia dos demais níveis de ensino e padrões mínimos de qualidade de ensino). Porém, como se tratam de deveres jurídicos, os agentes responsáveis por eles também podem ser penalizados por crimes de responsabilidade pelo descumprimento de tais deveres, ou se enquadrando na lei de improbabilidade administrativa, com hipótese de desvio de recurso público (Konzen, 1999). Como a relação comportamentoconsequência não é muito clara nos textos legais, assim como a diversidade de consequências, a decisão depende de interpretações judiciais, conforme as características do processo envolvido.

Além do Estado, a família também tem deveres com a educação. No Art. $6^{\circ}$ da $L D B$ observamos que é dever da família matricular seus filhos a partir dos seis anos de idade no ensino fundamental. As consequências para o descumprimento desse dever foram encontradas no $E C A$ : perda do poder familiar ou multa (Tabela 4).
Konzen (1999) ainda acrescenta que a falta do cumprimento deste dever por parte dos pais ou responsáveis também "pode significar a prática do delito de abandono intelectual” (p. 12), cuja consequência (pena) é detenção de quinze dias a um mês, ou multa (Art. 246 do Código Penal). Dessa forma, o comportamento de "não matricular" os filhos menores pode ter três consequências possíveis para os pais ou responsáveis (Art.24 e Art. 248 do ECA, e Art. 246 do Código Penal), que se resumem a perda de poder familiar, detenção e multa, cujo julgamento depende de interpretações do Poder Judiciário.

Ao longo da $L D B$ foi encontrada outra função da família na educação: juntamente com a escola e professores, os pais ou responsáveis têm a obrigação de acompanhar a frequência escolar do educando. Porém, na referida lei não há previsão de consequências contingentes a esse comportamento. $\mathrm{Na} L D B$ "acompanhar frequência escolar" não é tido como dever, enquanto no ECA ela consta como dever inerente ao pátrio poder (Art.129), e tem como consequência pelo descumprimento a pena de multa de três a vinte salários, aplicando-se o dobro em caso de reincidência (Art.249 do ECA).

Observa-se, então, que as tríplices contingências completas, e aquelas que foram completadas com artigos de outras leis, referem-se ao ensino fundamental, envolvendo consequências que controlam a garantia de sua oferta, acesso, matrícula e permanência.

As consequências encontradas são contingentes ao "descumprimento" de uma ação, ou seja, o Estado e a família têm deveres com a educação, mas não estão descritas consequências para "cumprimento" de tais deveres, e sim consequências aversivas para seu "descumprimento", reforçando, assim, o caráter punitivo do governo. Por outro lado, as contingências incompletas, por não esclarecerem as consequências para a ação (ou falta dela), abrem precedente para várias interpretações, que podem ser manipuladas, articulando-se com diferentes artigos de leis semelhantes. Diante disso, Todorov (2004) aponta a necessidade de análises que façam inter-relações com outras leis correlatas, ou seja, recorrer a artigos de outras leis para especificar consequências que faltam nas contingências incompletas da lei em estudo.

Desta forma, o controle legal envolve um emaranhado de leis, exercendo maior controle do comportamento do cidadão pela agência governamental (Skinner, 1953), uma vez que as leis que abordam o mesmo tema se inter-relacionam, por meio de repetição de artigos ou fornecendo elementos da contingência uma para outra.

Como segunda parte de análises, a $L D B$ é, também, um enunciado de metacontingências, pois descreve diversas contingências de vários segmentos da sociedade (União, estado, Distrito Federal, municípios, escola, educadores, família) que agem em regime de colaboração por uma educação universal e de qualidade, visando à melhoria da qualidade de vida dos cidadãos.

Na metacontingência principal, descrita no Art.2, foram identificados um produto agregado (PA) principal e dois PA secundários (Figura 3); destes últimos, apenas um foi definido em PA terciário (Tabela 5); para o outro 
apenas foram identificados meios para alcançá-lo. Desta forma, a $L D B$ define um PA (pleno desenvolvimento do educando) que depende dos outros (preparação para o exercício da cidadania e qualificação para o trabalho).

O PA secundário "preparo para exercício da cidadania" é definido, na $\angle D B$, em dois grupos de PA terciários (Tabela 5). A preparação para o exercício da cidadania é um dos objetivos da educação, já que ninguém nasce sabendo exercer todos os privilégios e obrigações inerentes à condição de cidadão. Por meio da educação, o cidadão passa a conhecer suas liberdades, formas de exercer seus direitos e a importância de cumprir seus deveres (Braatz, 2008; Machado, 1999; Pereira \& Teixeira, 2008).

Esse PA secundário é atingindo por meio do ensino fundamental (formação do cidadão) e do ensino médio (continuação de formação do cidadão e qualificação para trabalho), com predomínio no primeiro.

O PA secundário "qualificação para o trabalho" não pode ser definido em outros PA terciários. Tal dificuldade pode estar relacionada à grande variedade de modalidades de trabalho e profissões. Por isso, foram identificados meios de atingir esse PA secundário, que são: ensino médio, educação profissional e tecnológica, ensino superior e educação especial.

$\mathrm{O}$ ensino médio e superior tem funções formativa e profissional, com ênfase na primeira, enquanto a educação profissional tem como objetivos a formação técnica, a qualificação, a profissionalização e a atualização tecnológica, sendo desenvolvida em diferentes níveis de escolaridade, ou seja, sendo articulada à educação básica (Tabela 6), promovendo uma interação entre objetivo e conteúdos, principalmente com o ensino médio (Messeder, 2012; Pereira \& Teixeira, 2008).

A educação de jovens e adultos e a educação especial, que são modalidades de ensino, agem com o objetivo de cumprir de maneira satisfatória, conforme suas particularidades, sua função de preparar os educandos para exercício da cidadania e para o mundo do trabalho (Messeder, 2012; Pereira \& Teixeira, 2008). Para desenvolver um bom desempenho no preparo para o trabalho é necessário que o educando tenha adquirido habilidades/repertórios básicos, tais como aprendizagem de leitura, escrita e matemática, entre outras que são desenvolvidas no ensino fundamental.

\section{CONCLUSÕES}

Diante o exposto, conclui-se que a $\angle D B$, enquanto enunciado de contingências, apresenta consequências contingentes ao descumprimento de garantir acesso e permanência no ensino fundamental, ao passo que, enquanto enunciado de metacontingências, especifica o que tem que ser feito na educação nacional, que PAs devem ser atingidos, porém não expõe como fazer para alcançá-los, nem o que pode acontecer se nada disso ocorrer.

Além do mais, a $L D B$ elenca deveres de cada agente responsável pela educação, enfatizando que devem agir em regime de colaboração, porém não está claro como deve ser essa colaboração, nem como tais deveres devem ser executados. E nela nem é apresentada explicitamente qualquer consequência cultural contingente ao PA "pleno desenvolvimento do educando", e nem às suas definições em PAs secundários (preparo para o exercício da cidadania e qualificação para o trabalho). Porém, conforme a Constituição, a educação faz parte dos direitos sociais, direitos fundamentais inerentes da sociedade, e como tal ela visa à melhoria de condição de vida do detentor desses direitos (Braatz, 2008; Pereira \& Teixeira, 2008), ou seja, a consequência cultural que controla os PAs da $L D B$ é a melhoria na qualidade de vida dos cidadãos.

$\mathrm{O}$ direito à educação abrange direito à vaga, ao ingresso, à permanência, à qualidade de ensino e ao sucesso escolar. Tais características são abordadas, bem similarmente, na Constituição Federal, no Estatuto da Criança e do Adolescente, e na $L D B$, sendo que esta se concentra na oferta e regulação dos sistemas de ensino. E todos apresentam a obrigatoriedade do ensino fundamental (Konzen, 1999).

\section{REFERÊNCIAS}

Braatz, T. H. (2008) Direito à educação: dever do Estado? Revista Jurídica-CCJ/FURB, 12, 80-94.

Brasil. Código Penal Brasileiro (1940). Decreto-lei $n^{\circ} 2.848$, de 7 de dezembro de 1940. Rio de Janeiro: Presidência da República.

Brasil. Constituição da República Federativa do Brasil. (1988). Texto Constitucional promulgado em 5 de outubro de 1988. Diário Oficial da República $n^{\circ} 1988$. Brasília: Câmara dos Deputados.

Brasil. Decreto Lei n ${ }^{\circ}$ 201/67 de 27 de fevereiro. Diário Oficial da República $n^{\circ}$ 14.3/67. Brasília: Presidência da República.

Brasil. ECA: Estatuto da Criança e do Adolescente (1990). Lei $n^{\circ}$ 8.069, de 13 de junho de 1990. Conselho Nacional dos Direitos da Criança e do Adolescente. Brasília.

Brasil. LDB: Lei de Diretrizes e Bases da Educação Nacional. (1996). Lei $\mathrm{n}^{\circ} 9394$, de 20 de dezembro de 1996. Diário Oficial da República $n^{\circ 23.12 / 96 .}$ Brasília: Presidência da República.

Brasil. Lei $1079 / 50$ de 10 de abril. Diário Oficial da República $n^{\circ} 12.4 / 50$. Rio de Janeiro: Presidência da República.

Brasil. Lei 7106/83 de 28 de junho. Diário Oficial da República $n^{\circ} 7106 / 83$. Brasília: Presidência da República.

Castro, M. L. O. (2007). A educação brasileira nos dez anos de LDB. Textos para Discussão, 33.

Coffee Jr., J. C. (2011). Systemic risk after Dodd-Frank: Contingent capital and the need for regulatory strategies beyond oversight. Columbia Law Review, $111,795-847$.

Cury, C. R. J. (2002). A educação básica no Brasil. Educação \& Sociedade, 23, 168-200.

Dittrich, A., Todorov, J. C., Martone, R. C., \& SénéchalMachado, V. L. (2013). Agências de controle. Em M. B. Moreira (Org.), Comportamento e Práticas Culturais (pp. 137-167). Brasília: Instituto Walden4. 
Ellis, J., \& Magee, S. (2007). Contingencies, macrocontingencies, and metacontingencies in current educational practices: No child left behind? Behavior and Social Issues, 16, 5-26.

Glenn, S. (1991). Contingencies and metacontingencies: Relations among behavioral, cultural, and biological evolution. In P. A. Lamal (Ed.), Behavioral analysis of societies and cultural practices (pp. 39-73). Washington, DC: Hemisphere.

Glenn, S. S. (2004). Individual behavior, culture, and social change. The Behavior Analyst, 27, 133-151.

Glenn, S. S. (2010). Metacontingencies, selection and OBM: Comments on "Emergence and Metacontingency". Behavior and Social Issues, 19, 7985.

Konzen, A. A. (1999). O direito à educação escolar. Em: L.N. Brancher, M.M. Rodrigues, \& A.G. Vieira (Orgs). $O$ direito é aprender (pp. 09-15). Brasília: MEC.

Machado, L. M. (1999). A nova LDB e a construção da cidadania. Em: C. S. B. Silva, \& L. M. Machado. Nova LDB: Trajetória para cidadania? (93-104), São Paulo, Arte \& Ciência.

Malott, M. E., \& Glenn, S. S. (2006). Targets of intervention in cultural and behavioral change. Behavior and Social Issues, 15, 31-36.

Martins, A. L. A. (2008). O Sistema Único de Saúde: contingências e metacontingências nas Leis Orgânicas da Saúde. Dissertação de mestrado em Ciências do Comportamento. Universidade de Brasília, Brasília.

Messeder, H. (2012). Entendendo a LDB: Lei de Diretrizes e Bases da Educação Nacional. Rio de Janeiro: Elsevier.

Moraes, A (2001). Direito constitucional. São Paulo: Atlas.

Pereira, E. W. \& Teixeira, Z. A. (2008). Reexaminando a educação básica na LDB: o que permanece e o que muda. Em: I. Brzezinski (Org.) LDB dez anos depois: reinterpretações sob diversos olhares (p. 99-129) São Paulo: Cortez.

Silva, A. L. (2008). Evolução de práticas culturais: a análise de uma organização autogestionável. Tese de Doutorado em Ciências do Comportamento. Universidade de Brasília, Brasília.
Skinner, B. F. (1953). Science and human behavior. New York: Macmillan.

Skinner, B. F. (2000). Ciência e comportamento humano (J. C. Todorov, \& R. Azzi, Trad.). São Paulo: Martins Fontes.

Todorov, J. C. (1991). O conceito de contingência na psicologia experimental. Psicologia: Teoria $e$ Pesquisa, 7, 59-70.

Todorov, J. C. (2004). Da aplysia à constituição: Evolução de conceitos na análise do comportamento. Psicologia: Reflexão e Crítica, 17, 151-156.

Todorov, J. C, (2005). Laws and the complex control of behavior. Behavior and Social Issues, 14, 86-90.

Todorov, J. C. (2009). Behavioral analysis of nonexperimental data associated with cultural practices. Behavior and Social Issues, 18, 10-14.

Todorov, J. C. (2010). Schedules of cultural selection: Comments on "Emergence and Metacontingency". Behavior and Social Issues, 19, 86-89.

Todorov, J. C. (2012 a). A psicologia como o estudo de interações. Brasília, DF: Editora Walden4.

Todorov, J. C. (2012 b). Metacontingências e a análise comportamental de práticas culturais. Clínica \& Cultura, 1, 36-45.

Todorov, J. C. (2013). Conservation and transformation of cultural practices through contingencies and metacontingencies. Behavior and Social Issues, 22, 6473.

Todorov, J. C., Moreira, M., Prudêncio, M. R. A., \& Pereira, G. C. C. (2004). O Estatuto da Criança e do Adolescente como metacontingência. In M. Z. S. Brandão, F. C. S. Conte, F. S., Brandão, Y. K. Ingberman, V. L. M. Silva, \& S. M. Oliani (Orgs.), Sobre comportamento e cognição: contingências $e$ metacontingências, contextos sócio-verbais e o comportamento do terapeuta (Volume 13, pp. 44-51). Santo André, SP: ESETec.

Submetido em 02/12/2014 Aceito em 04/10/2016 